\title{
Selection of optimal electric vehicle charging station location using AHP-fuzzy TOPSIS approach
}

\author{
Aman Dhingra ${ }^{1}$, Avnish Jareda ${ }^{2}$, Himanshu Choudhary ${ }^{3}$, Dr.Saurabh Agrawal ${ }^{4}$ \\ \{amandhingra_bt2k16@dtu.ac.in ${ }^{1}$, avnishjareda23@gmail.com², himanshu280598@gmail.com ${ }^{3}$ \}
}

B.Tech Student, Department of Mechanical Engineering, Delhi Technological University, Delhi, India ${ }^{1,2,3}$ Assistant Professor, Department of Mechanical Engineering, Delhi Technological University, Delhi, India ${ }^{4}$

\begin{abstract}
Electric vehicles have developed into one of the most desirable transportation alternatives in recent times. India and many countries such as the USA and the UK are working on various projects and policies to increase the amount of electrically powered vehicles onto their roads soon to deal with continuously rising fuel prices and $\mathrm{CO} 2$ emissions. For effective implementation of such plans, suitable charging infrastructure requires supplying the electrical fuel to these vehicles. In this paper, we studied and different types of factors, such as traffic density, weather, parking space, solar power capacity, and many other factors, to identify the optimum location for public charging stations within a specified area with the help of AHP-fuzzy TOPSIS approach.
\end{abstract}

Keywords: electric vehicles; optimum location; AHP; Fuzzy TOPSIS.

\section{Introduction}

The concept of electric cars first came into existence in the mid-nineteenth century. The rising awareness about carbon footprint and other environmental impacts of fossil-fuel-based vehicles increased their popularity. Therefore, such vehicles act as a possible replacement for currentgeneration automobiles due to technological developments and even as the "green saviour," to counter the rising problems of pollution, global warming, depletion of natural resources, etc. [1]. Electric vehicles run at low maintenance costs as they have less moving parts and no requirement for lubricating the engine. They also reduce noise pollution; therefore, they produce less noise and are smooth driven [2]. However, the sales figures for EVs around the globe show limited adoption of electric vehicles. The prime reasons for this are the high cost of EVs and short driving ranges. Besides, insufficient battery technologies and long-time consumption during charging make them less attractive to the market. Furthermore, adopting the latest technology and the lack of faith in electricity, as fuel is also one of the reasons people are not willing to make these changes [1]. 
In India, the government has been working on the projects and policies for the development of electric vehicles for around a decade.

Analytic Hierarchy Process is one of the popular analytic methods for complex decision-making problems developed by SATTY, which breakdowns the decision-making problem into a structured system of hierarchy of objectives, criteria, and alternatives. Hwang and Yoon developed the TOPSIS method in 1981. It is based on the approach that the chosen decision should have the minimum Euclidean distance from the ideal solution and maximum from the negative ideal solution [3].

\section{Literature review}

Muniamuthu et al. pointed out the rise in demand for electric vehicles, their sales, increasing their adoption, and the increase in government policies to promote the usage of electric vehicles. Showing the widespread determination to shift from pollution-causing conventional automobiles to electric vehicles [4]. Lie et al. explained about the evolution of electric cars, pros and cons, their sources of supply, their classification and constituents [5] and for the charging of electric cars, Somudeep et al. explained about the various categories of public charging sites and factors involved in the picking the most suitable location for installation of a public charging infrastructure in urban areas or developed cities [6]. The charging station model needs planning before establishment to minimise investments and operating costs. Zhang et al. considered that thoughtful outlining and massive scale development of charging facilities is a prerequisite for the popularisation and application of electric vehicles and to solve the problem of energy shortage and environmental pollution [7]. Khooi et al. talked about the methods of planning and strategic management of electric vehicle charging sites in the research and how effective planning and management play an essential role in the replacement of fossil fuel by hybrid or electric vehicles [8]. Yin et al. introduced a planning model charging infrastructure by combining aspects of the networks of road, traffic flow, and space constraints to determine the charging demands of the traffic flow and optimise the charging facility location accordingly [9].

González et al. studied the daily dimensional behaviour of electric vehicles (EV) and trip durations to design an algorithm for the identification of optimal locations and identify the most overloaded area [10]. Erbaş et al., with the help of Geographic Information Systems (GIS), a decision support system, and the Analytical Hierarchy Process (AHP), constructed a study to determine the best location for charging from the selected area of Istanbul, Turkey [11]. Wu et al., in his paper, proposed a decision system based on Preference Ranking Organization Method for Enrichment Evaluations (PROMETHEE) method and merged it with the cloud model to simplify the task of selection of an ideal site for the electric vehicle charging station. The technique used in this paper also makes up for the flaws in the traditional MCDM methods [12]. Andrenacci et al. analysed an extensive collection of vehicle movement data to carry out a strategy for the best possible location of the charging station to meet the demand [13]. Viswanathan et al. studied the real traffic flow and road system data and the movement of each vehicle plying on the road to determine the charging station framework [14]. 


\section{Research methodology}

First, we studied the importance of electric vehicle charging stations and why they need preference in the future. The primary component of the electric vehicle system is the charging station location. Thus, we need to determine factors, which will help in deciding the optimum location for the charging station. We talked with various experts from the automobile department in Hyundai, Tata Motors, and Mahindra. Next, we determined the factors based on the experience of different automobile professionals from various sectors. Experts mentioned above further reviewed our analysis and which helped us to draw necessary outcomes for the establishment of factors affecting the electric vehicle charging station. For choosing the most appropriate locations for charging stations, we employed AHP to obtain the weights of the criteria, while TOPSIS determines the priorities of alternatives.

\section{Factors affecting the location of the electric vehicle charging station}

While deciding a place for the installation of an electric vehicle, it is vital to consider the following factors to develop an electric vehicle charging station, which is economically viable and readily accepted.

\section{- $\quad$ Area of electric vehicle station}

Larger the useful space of the electric vehicle station, a number of the vehicle can be accommodated and charged, and new equipment placed quickly. The designer generally recommends parking lot either perpendicular or angled to traffic flow as it has high spatial efficiency. Angled parking lot creates unused triangular spaces suitable for electric vehicle supply equipment [15].

- Charging duration

Charging duration means "how long does it take to charge the electric vehicle." The electric vehicle charging station can be located at places which are accessible to people such as shopping malls, educational organisations, and workplaces so that less time of people will be wasted for their electric vehicles to charge [6]. Level 1, level 2, level 3 charging equipment used depends upon the time the car spends in the charging station.

\section{- $\quad$ Traffic density}

Traffic density is an essential factor as it is directly proportional to the number of users. With an increase in traffic density, many users can use the charging station for their electric vehicle charging. With the installation of fast charging equipment, a large number of vehicles get charging, thus fulfilling the need for more users. Since densely populated location has costly land value, it is challenging to build a charging station, but places like a shopping centre, workplace, and government offices can work. Multiple floors charging stations can make to incorporate many users. Thus, it is more favourable to build a charging station where traffic density is more. 


\section{- Integrating with existing infrastructure}

Electric vehicle charging is generally located in place, having a mix of buildings, other structures, walkways, and parking lots. Hence, proper formal and informal Pedestrians should have designed before placing the electric vehicle charging station so that cables do not create a tripping hazard. Vandalism and personal safety are essential characteristics of which care must take for enhanced utilisation of electric vehicle stations. Electric vehicle stations should accommodate the person with disabilities.

\section{- $\quad$ Surrounding vehicle movement}

Public electric vehicle charging stations cause various effects on the environment around them. The location of the charging station should be as such that the charging vehicles must not hinder the normal flow of traffic. Moreover, the incoming charging vehicles should not become a hurdle for pedestrian traffic and other vehicles and do not cause any accident or vandalism. One of the best ways of the implication of the charging station is along the street side parking bays [6].

\section{- Communication}

Information and technology support, control, manage the energy transfer between the electric vehicle and power grid varying in time and space. Technology further needed for management, billing, information, and authorisation for energy transfer. Internet technology plays a vital role in load management, thus leading to the optimisation of resources. Facilities like free Wi-Fi and appconnected electric vehicle charging stations can attract the consumer. Therefore adequate information technology is required for the general and more accessible operation of electric vehicle charging stations. Proper Network communication needs to display information on the screen, manage demand-supply and report faulty equipment, etc.

\section{- Weather}

The weather must not hinder the functioning of electric vehicles. In winter, the location must not be affected by snow, fog, ice, etc. Snow, ice can damage the equipment and impede the operation. Fog reduces the visibility level, thus leading to accidents. For this, the closed and covered type charging station work and should use photovoltaic charging technology [16].

\section{- Visibility}

Visibility of the charging station is an essential factor in encouraging the use of the station by the drivers and increases the number of users. The charging station should be easily visible to the drivers from distant places, as it will help the users in locating charging stations quickly and attracting more users. The visibility of the charging station can enhance with the help of signboards and indicators [6].

\section{Analytic Hierarchy Process (AHP)}

AHP is the most comprehensive system considered deciding with multiple criteria because this method gives to formulate the problem as hierarchical. The step by step approach given below:

Step 1: Define the objective and their decision criteria and sub-criteria.

Step 2: Construct a pairwise comparison matrix having (k) elements by comparing the importance of each criterion with all other criteria's with the help of a specified scale of preference ranging from 1 to 9 , as shown in Table 1 [17]. 
Table 1. Scale of preference

\begin{tabular}{ll}
\hline Weights & Meaning \\
\hline 1 & Equally important \\
3 & Moderate \\
5 & Strong \\
7 & Very strong \\
8 & Extreme \\
$2,4,6,8$ & Intermediate values \\
Reciprocals & Reciprocals of opposite evaluation \\
\hline
\end{tabular}

Step 3: Normalised pairwise comparison matrix is calculated by dividing all elements of a column by the sum of the column. Now criteria weights are calculated by averaging all elements in a row. Now maximum Eigen value $\lambda_{\max }$ of the matrix is calculated. The consistency index (CI) calculated as:

$$
\mathrm{CI}=\frac{\left(\lambda_{\max }-\mathrm{k}\right)}{(\mathrm{k}-1)}
$$

Step 4: To calculate random index (RI) use Table 2 [17] and the following relation obtains consistency ratio (CR):

$$
\mathrm{CR}=\frac{\mathrm{CI}}{\mathrm{RI}}
$$

If $(C R)$ is $\leq 0.1$, then the matrix is consistent and acceptable. If the (CR) is $\geq 0.1$, the matrix is inconsistent, and judgment is not accurate.

Table 2. Values of random index

\begin{tabular}{lcccccccccc}
\hline No.of attribute $(\mathrm{k})$ & 1 & 2 & 3 & 4 & 5 & 6 & 7 & 8 & 9 & 10 \\
RI & 0.00 & 0.00 & 0.58 & 0.90 & 1.12 & 1.24 & 1.32 & 1.41 & 1.45 & 1.49 \\
\hline
\end{tabular}

\section{The Technique for Order of Preference by Similarity to Ideal Solution (TOPSIS)}

TOPSIS compares a set of choices by identifying weights of each criterion, then normalising the value of each of them and determining the geometric distance between each alternative and ideal alternative, which is the optimal value in each criterion. The step by step approach given below:

Step 1: Generate feasible alternatives and determine the evaluation criteria. Assume that there are ' $a$ ' alternative and ' $b$ ' evaluation criteria. 
Step 2: Choose the linguistic ratings for alternatives concerning standards from Table 3 [18].

Table 3. Linguistic terms and fuzzy numbers

\begin{tabular}{ll}
\hline Linguistic term & Fuzzy number \\
\hline Very low & $(0.0,0.1,0.3)$ \\
Low & $(0.1,0.3,0.5)$ \\
Medium & $(0.3,0.5,0.7)$ \\
High & $(0.5,0.7,0.9)$ \\
Very high & $(0.7,0.9,1.0)$ \\
\hline
\end{tabular}

Step 3: Construct the fuzzy decision matrix as given below.

$$
\mathrm{M}=\left[\begin{array}{cccccc}
\mathrm{z}_{11} & \mathrm{z}_{21} & \mathrm{z}_{31} & \ldots & \ldots & \mathrm{z}_{1 \mathrm{~b}} \\
\mathrm{z}_{21} & \mathrm{z}_{22} & \mathrm{z}_{32} & \ldots & \ldots & \mathrm{z}_{2 \mathrm{~b}} \\
\ldots & \ldots & \ldots & \ldots & \ldots & \ldots \\
\ldots & \ldots & \ldots & \ldots & \ldots & \ldots \\
\ldots & \ldots & \ldots & \ldots & \ldots & \ldots \\
\mathrm{z}_{\mathrm{a} 1} & \mathrm{z}_{\mathrm{a} 2} & \mathrm{z}_{\mathrm{a} 3} & \ldots & \ldots & \mathrm{z}_{\mathrm{ab}}
\end{array}\right] .
$$

Where $z_{i j}=\left(e_{i j}, f_{i j}, g_{i j}\right)$ is the fuzzy number, $i=1,2 \ldots$, a represents the alternatives and $j=1,2 \ldots$, $b$ represents the criteria.

Step 4: Now neutralise the weights of the matrix and generate the un-weighted matrix (S). Matrix $\mathrm{S}$ is obtained using the following relationship:

$$
S=\left[S_{i j}\right]_{a x b} ; s_{i j}=\left(\frac{e_{i j}}{d_{j}^{*}}, \frac{f_{i j}}{d_{j}^{*}}, \frac{g_{i j}}{d_{j}^{*}}\right) \quad \text { where } d_{j}^{*}=\max d_{i} \text {. }
$$

Step 5: Calculate the normalized weighted decision matrix as given below

$$
\mathrm{H}=\left[\mathrm{h}_{\mathrm{ij}}\right]_{\mathrm{axb}} ; \mathrm{i}=1,2, \ldots \mathrm{a} ; \mathrm{j}=1,2, \ldots \mathrm{b} .
$$

The normalized weighted value $h_{i j}$ given as:

$$
h_{i j}=s_{i j} \times w_{j} .
$$

Here $w_{j}$ denotes the weight of the $j^{\text {th }}$ criteria as calculated above.

Step 6: Obtain the ideal positive and negative solution:

$$
D^{+}=\left\{u_{1}^{+}, u_{2}^{+}, \ldots . . u_{n}^{+}\right\} \& D^{-}=\left\{u_{1}^{-}, u_{2}^{-}, \ldots . . u_{n}^{-}\right\} .
$$

The positive and negative ideal solution is given below: 


$$
u_{j}^{+}=(1,1,1) \& u_{j}^{-}=(0,0,0)
$$

Step 7: Determine the distances from $\mathrm{D}^{+}$and $\mathrm{D}^{-}$for every factor by using

$$
\mathrm{d}(\mathrm{D} 1-\mathrm{D} 2)=\sqrt{\frac{1}{3}\left[\left(\mathrm{e}_{2}-\mathrm{e}_{1}\right)^{2}+\left(\mathrm{f}_{2}-\mathrm{f}_{1}\right)^{2}+\left(\mathrm{g}_{2}-\mathrm{g}_{1}\right)^{2}\right]} .
$$

Step 8: Calculate the relative closeness coefficient given by:

$$
\mathrm{CC}_{\mathrm{j}}=\frac{\mathrm{D}_{\mathrm{j}}^{-}}{\mathrm{D}_{\mathrm{j}}^{+}+\mathrm{D}_{\mathrm{j}}^{-}}, \quad \mathrm{j}=1,2, \ldots \mathrm{b} .
$$

Step 9: Now rank the alternatives in descending order based on values of $\mathrm{CC}_{\mathrm{j}}$.

\section{Numerical application}

AHP-TOPSIS approach is utilised in the problem for the selection of optimal charging station locations. The problem is demonstrated in the hierarchy of three stages, as shown in Figure 1. The first stage shows the problem objectively. The next step defines the criteria about the top stage, and the last step shows the alternatives.

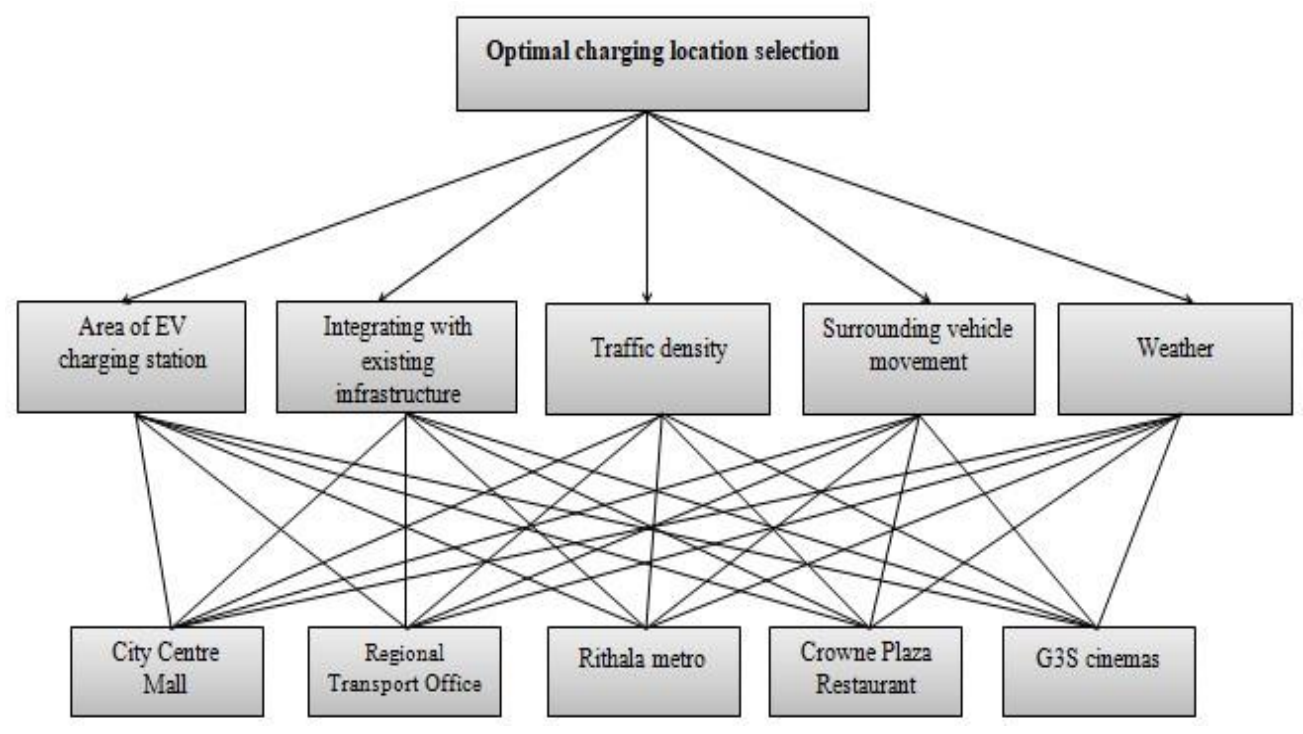

Figure 1. Levels of hierarchy 
The criteria that we identified were the area of electric vehicle charging station (CR1), integrity with existing infrastructure (CR2), traffic density (CR3), surrounding vehicle movement (CR4), and weather (CR5). After this, the AHP approach followed, and the pairwise criteria matrix constructed, and the criteria weights determined are presented in Table 4 . Now the values of $\lambda_{\max }$, $\mathrm{CI}, \mathrm{RI}$, and CR calculated, as shown in equation (11). The consistency ratio is less than 0.1 , which is acceptable. We can now proceed with the TOPSIS method. Here we have chosen Rohini, New Delhi, India, as the area where we wish to put up the electric vehicle charging station. We selected five potential locations. The locations are City Centre Mall, Rohini sector-10 (L1), Regional Transport Office, Rohini sector-16 (L2), Rithala Metro Station, Rohini (L3), Crowne Plaza Restaurant, Rohini sector-10 (L4) and G3S Cinemas, Rohini sector-11 (L5). The fuzzy evaluation matrix, as illustrated in Table 5, drawn then the fuzzy weighted matrix, as shown in Table 6 and subsequent TOPSIS steps followed. The overall values represented in Table 7.

Table 4. Pairwise comparison of all criteria

\begin{tabular}{lllllll}
\hline Criteria & CR1 & CR2 & CR3 & CR4 & CR5 & Weight \\
\hline CR1 & 1 & $1 / 5$ & $1 / 3$ & 3 & 3 & 0.144 \\
CR2 & 5 & 1 & 5 & 6 & 6 & 0.537 \\
CR3 & 3 & $1 / 5$ & 1 & 2 & 2 & 0.173 \\
CR4 & $1 / 3$ & $1 / 6$ & $1 / 2$ & 1 & 2 & 0.084 \\
CR5 & $1 / 3$ & $1 / 6$ & $1 / 2$ & $1 / 2$ & 1 & 0.062 \\
\hline
\end{tabular}

$$
\lambda_{\max }=5.40, \mathrm{CI}=0.10, \mathrm{RI}=1.12, \mathrm{CR}=0.089 .
$$

Table 5. Evaluation matrix

\begin{tabular}{llllll}
\hline & CR1 & CR2 & CR3 & CR4 & CR5 \\
\hline L1 & $(0.5,0.7,0.9)$ & $(0.5,0.7,0.9)$ & $(0.3,0.5,0.7)$ & $(0.7,0.9,1.0)$ & $(0.3,0.5,0.7)$ \\
L2 & $(0.5,0.7,0.9)$ & $(0.5,0.7,0.9)$ & $(0.3,0.5,0.7)$ & $(0.3,0.5,0.7)$ & $(0.5,0.7,0.9)$ \\
L3 & $(0.7,0.9,1.0)$ & $(0.7,0.9,1.0)$ & $(0.7,0.9,1.0)$ & $(0.3,0.5,0.7)$ & $(0.3,0.5,0.7)$ \\
L4 & $(0.5,0.7,0.9)$ & $(0.3,0.5,0.7)$ & $(0.3,0.5,0.7)$ & $(0.3,0.5,0.7)$ & $(0.3,0.5,0.7)$ \\
L5 & $(0.7,0.9,1.0)$ & $(0.5,0.7,0.9)$ & $(0.7,0.9,1.0)$ & $(0.7,0.9,1.0)$ & $(0.7,0.9,1.0)$ \\
Weight & 0.144 & 0.537 & 0.173 & 0.084 & 0.062 \\
\hline
\end{tabular}

Table 6. Fuzzy weighted matrix

\begin{tabular}{llllll}
\hline & CR1 & CR2 & CR3 & CR4 & CR5 \\
\hline L1 & $(0.072,0.101,0.130)$ & $(0.269,0.376,0.483)$ & $(0.052,0.087,0.121)$ & $(0.059,0.076,0.084)$ & $(0.019,0.031,0.043)$ \\
L2 & $(0.072,0.101,0.130)$ & $(0.269,0.376,0.483)$ & $(0.052,0.087,0.121)$ & $(0.025,0.042,0.059)$ & $(0.031,0.043,0.056)$ \\
L3 & $(0.101,0.130,0.144)$ & $(0.376,0.483,0.537)$ & $(0.121,0.156,0.173)$ & $(0.025,0.042,0.059)$ & $(0.019,0.031,0.043)$ \\
L4 & $(0.072,0.101,0.130)$ & $(0.161,0.269,0.376)$ & $(0.052,0.087,0.121)$ & $(0.025,0.042,0.059)$ & $(0.019,0.031,0.043)$ \\
L5 & $(0.101,0.130,0.144)$ & $(0.269,0.376,0.483)$ & $(0.121,0.156,0.173)$ & $(0.059,0.076,0.084)$ & $(0.043,0.056,0.062)$ \\
\hline
\end{tabular}


Table 7. Overall values

\begin{tabular}{lllll}
\hline & $\mathrm{D}_{\mathrm{j}}^{+}$ & $\mathrm{D}_{\mathrm{j}}^{-}$ & $\mathrm{CC}_{\mathrm{j}}$ & Ranking \\
\hline $\mathrm{L} 1$ & 4.339 & 0.686 & 0.136 & 3 \\
$\mathrm{~L} 2$ & 4.358 & 0.669 & 0.133 & 4 \\
$\mathrm{~L} 3$ & 4.191 & 0.824 & 0.164 & 1 \\
$\mathrm{~L} 4$ & 4.477 & 0.553 & 0.110 & 5 \\
$\mathrm{~L} 5$ & 4.229 & 0.791 & 0.157 & 2 \\
\hline
\end{tabular}

\section{Conclusion}

The selection of a suitable site for the charging system is an essential activity for promoting electric vehicles and examination of multiple factors need to be satisfied for developing a commercially viable charging station. In this paper, we examined the various factors, which are suitable for selecting the electric vehicle charging station. For the selection of the most appropriate location, this paper proposed an integrated AHP and fuzzy TOPSIS method. AHP determines the weights of the criteria, while fuzzy TOPSIS determines the priorities of alternatives. The ranking of the locations in descending order is L3, L5, L1, L2, and L4. The proposed model results indicate that L3 is the best location among the five selected locations in the given area. Since we are pushing for electric vehicles, we need charging stations too, and to choose the proper location is a big challenge, which, if achieved, would be of utmost use. Our approach gets applicable to any given area or region and helps solve this problem by providing the optimum site for an electric vehicle charging station.

\section{References}

[1] Wagner, Sebastian, Markus Götzinger, and Dirk Neumann. Optimal location of charging stations in smart cities: A point of interest based approach. International Conference on Information Systems: Reshaping Society Through Information Systems Design. 2013. vol. 3. pp. 2838-2855.

[2] Rinkesh. (2016,December 25). Advantages and Disadvantages of Electric Cars. Retrived from https://www.conserve-energy-future.com/advantages-and-disadvantages-of-electric-cars.php.

[3] Ching-Lai Hwang, and Kwangsun Yoon. Multiple Attribute Decision Making. Lecture Notes in Economics and Mathematical Systems. Springer. Berlin Heidelberg. 1981.

[4] Sumathy Muniamuthu, S. Krishna Arjun, M. Jalapathy, S.Harikrisnan, and A. Vignesh. Review on electric vehicle. International Journal of Mechanical and Production Engineering Research and Development (IJMPERD). 2018. vol. 8. no. 2. pp. 557-566.

[5] Tek Tjing Lie, Krishnamachar Prasad, and Ning Ding. The electric vehicle: a review. International Journal of Electric and Hybrid Vehicles. 2017. vol. 9. pp. 49. 
[6] Somudeep Bhattacharjee, Saima Batool, Champa Nandi, and Udsanee Pakdeetrakulwong. Investigating Electric Vehicle (EV) Charging Station Locations for Agartala, India. The 2nd International Conference of Multidisciplinary Approaches on UN Sustainable Development Goals (UNSDGs). 2017. pp. 1-13.

[7] Mingsheng Zhang. Location Planning of Electric Vehicle Charging Station. IOP Conference Series: Materials Science and Engineering. 2018. vol. 394. no. 4. p. 042126.

[8] Hookah Khooi, and Rashad Yazdanifard. How to Plan and Strategically Manage an Electric Vehicle (EV) Charging Station. Global Journal of Management and Business Research. 2015. vol. 15. no. 4. pp. 1-5.

[9] Xiaoman Yin, and Xiangyang Zhao. Planning of Electric Vehicle Charging Station Based on Real Time Traffic Flow. Vehicle Power and Propulsion Conference (VPPC). IEEE. 2016.

[10] Jairo González, Roberto Alvaro, Carlos Gamallo, Manuel Fuentes, Jesús Fraile Ardanuy,Luk Knapen, and Davy Janssens. Determining Electric Vehicle Charging Point Locations Considering Drivers' Daily Activities. Procedia Computer Science. 2014. vol. 32. pp. 647-654.

[11] Mehmet Erbaş, Mehmet Kabak, Eren Özceylan, and Cihan Çetinkaya. Optimal siting of electric vehicle charging stations: A GIS based fuzzy Multi-Criteria Decision Analysis. Energy. 2018. vol. 163. pp. 1017-1031.

[12] Yunna Wu, Meng Yang, Haobo Zhang, Kaifeng Chen, and Yang Wang. Optimal Site Selection of Electric Vehicle Charging Stations Based on a Cloud Model and the PROMETHEE Method. Energies. 2016. vol. 9. pp. 157.

[13] Natascia Andrenacci, Roberto Ragona, and Gaetano Valenti. A demand-side approach to the optimal deployment of electric vehicle charging stations in metropolitan areas. Applied Energy. 2016. vol. 182. pp. 39-46.

[14] T. VaisaghViswanathan, Daniel Zehe, Jordan Ivanchev, Dominik Pelzer, Alois Knoll, Heiko Aydt. Simulation-assisted exploration of charging infrastructure requirements for electric vehicles in urban environments. Journal of Computational Science. 2016. vol. 12. pp. 1-10.

[15] Site-Design-for-EV-Charging-Stations.pdf(n.d.). Retrieved from https://www.nyserda.ny.gov/Researchers-and-Policymakers/Electric-Vehicles/Resources/BestPractice-Guides-for-Charging-Stations.

[16] Tom Lepley and Prem Nath. Photovoltaic covered-parking systems using lightweight, thinfilm PV. Conference Record of the Twenty Sixth IEEE Photovoltaic Specialists Conference. 1997. pp. 1305-1308.

[17] R.W. Saaty. The Analytic Hierarchy Process-What It Is and How It Is Used. Mathematical Modelling. 1987. vol. 9. no. 3-5. pp. 161-176.

[18] Chen-Tung Chen. Extensions of the TOPSIS for Group Decision-Making under Fuzzy Environment. Fuzzy Sets and Systems. 2000. vol. 114. no. 1. pp. 1-9. 